\title{
Age Differences in Genetic Knowledge, Health Literacy and Causal Beliefs for Health Conditions
}

\author{
S. Ashida ${ }^{a} \quad$ M. Goodman ${ }^{b} \quad$ C. Pandyab $\quad$ L.M. Koehly ${ }^{a} \quad$ C. Lachance ${ }^{a} \quad$ J. Stafford ${ }^{b}$ \\ K.A. Kaphingst ${ }^{a}$ \\ a Social and Behavioral Research Branch, National Human Genome Research Institute, Bethesda, Md., and \\ ${ }^{b}$ Graduate Program in Public Health, Department of Preventive Medicine, Stony Brook University, New York, N.Y., USA
}

\section{Key Words}

Causal beliefs $\cdot$ Community-based sample $\cdot$ Genetic

communication $\cdot$ Genetic knowledge $\cdot$ Health literacy

\begin{abstract}
Objectives: This study examined the levels of genetic knowledge, health literacy and beliefs about causation of health conditions among individuals in different age groups. Methods: Individuals $(n=971)$ recruited through 8 community health centers in Suffolk County, New York, completed a one-time survey. Results: Levels of genetic knowledge were lower among individuals in older age groups $(26-35, p=$ $0.011 ; 36-49, p=0.002 ; 50$ years and older, $p<0.001$ ) compared to those in the youngest age group (18-25). Participants in the oldest age group also had lower health literacy than those in the youngest group $(p<0.001)$. Those in the oldest group were more likely to endorse genetic $(O R=1.87$, $p=0.008$ ) and less likely to endorse behavioral factors like diet, exercise and smoking $(O R=0.55, p=0.010)$ as causes of a person's body weight than those in the youngest group. Higher levels of genetic knowledge were associated with higher likelihood of behavioral attribution for body weight $(\mathrm{OR}=1.25, \mathrm{p}<0.001)$. Conclusions: Providing additional in-
\end{abstract}

\section{KARGER}

Fax +4161306 1234

E-Mail karger@karger.ch

www.karger.com (c) 2010 S. Karger AG, Basel

Accessible online at: www.karger.com/phg formation that compensates for their lower genetic knowledge may help individuals in older age groups benefit from rapidly emerging genetic health information more fully. Increasing the levels of genetic knowledge about common complex diseases may help motivate individuals to engage in health promoting behaviors to maintain healthy weight through increases in behavioral causal attributions.

Copyright $\odot 2010$ S. Karger AG, Basel

\section{Introduction}

In recent years, there has been a rapid increase in the availability of genetic information regarding common health conditions, such as heart disease and diabetes, which concerns a large proportion of the population $[1$, 2]. Experts in the field expect that this development will help improve medical care and public health efforts through personalization of health information (e.g. tailored risk information and prevention recommendations) $[3,4]$. It is projected that an increasing number of people will encounter genetic information and face the need to make health decisions associated with such information. Thus, it is imperative to assess individuals' levels 
of understanding of genetic information and how such information is perceived. This will allow for the development of evidence-based culturally appropriate strategies designed to assist individuals in informed decision-making based on genetic advancements.

The knowledge related to genetic sciences among the public has been qualitatively evaluated in the U.S. and shown to be rather limited [5] and often scientifically inaccurate [6]. Much of the large scale work on this topic has been conducted outside of the U.S. [7], and has shown that lower levels of knowledge about genetics were associated with less endorsement for genomic studies and technologies, suggesting that the extent to which individuals understand genetic information may have implications for whether it is used. For example, those with lower levels of scientific knowledge related to genes were more likely to be opposed to the use of biotechnology, independent of their gender and education levels, among a nationally representative sample of adults in European Union countries [8]. Similarly, among a nationally representative sample of adults in Britain, across social groups, those with lower knowledge of genetics showed less support for genetic science and research [9]. Knowledge about genetic concepts is one aspect of health literacy, and the importance of sufficient genetic knowledge in health care decision-making is increasingly being noted. In recognition of this, the U.S. Surgeon General's Family History Initiative identifies augmenting 'genetic literacy' among American adults as one of their primary goals [10].

Genetic literacy, or 'sufficient knowledge and appreciation of genetic principles to allow informed decisionmaking for personal well-being and effective participation in social decisions on genetic issues [11],' can be considered to be a specific context for overall health literacy that is rapidly increasing in importance in improving the health of our population [10]. Although a comprehensive measure of genetic literacy for college students is now being developed [11], such a tool is not readily available to evaluate levels among the general public. Because health literacy (i.e. skills and knowledge related to health information) is critical in the dissemination of genetic information [12], the assessment of levels of genetic knowledge together with the assessment of general health literacy can provide an estimate of genetic literacy in a population.

Although health literacy has not previously been examined in the context of genetics, studies have consistently shown a negative association between age and health literacy among adults [13-15], even after adjusting for potential confounders such as race, ethnicity, education levels, cognitive ability, health status, and visual acuity [16]. In the U.S., the highest average health literacy has been found among those ages $25-39$, and the average levels decreased with increasing age [17]. Thus, age has been identified as one of the contributors for health disparities observed in our society [18] as it influences the ability of subgroups of individuals to fully benefit from health or health care related information, leading to an increased risk for poorer health outcomes. Evidence also shows that low levels of health literacy are associated with less engagement in preventive health behaviors and poorer health outcomes $[19,20]$. Because morbidity, mortality and healthcare utilization increase with age [21,22], individuals may become increasingly vulnerable as they age and may be disproportionately negatively affected by low literacy levels. Furthermore, it is likely that the genetic information generated by recent research concerning common complex diseases is highly salient to individuals of late middle-age or older because of an increasing prevalence of chronic diseases and healthcare utilization [21], and those in this age group may need to make healthrelated decisions increasingly involving genetics.

Prior research showing that individuals in different age strata or cohorts may respond differently to healthrelated information has considered potential reasons for such age differences $[13,16]$. For example, individuals may experience physical or cognitive changes as they age that may influence the way they read, comprehend or act upon provided information (aging effects). Factors that influence how individuals process information, such as decreasing visual acuity, lower frequency of reading behaviors and an increase in prevalence of chronic diseases in late middle-age have been highlighted as potential reasons (see Baker et al. [16] for a review). Furthermore, individuals who were born in a different historical time experience very different life events as they age (cohort effects) [23]. Thus, considering the rapid pace of scientific advancement over the past decades, it is likely that individuals who are currently in their 20 s received different health or genetic education in school as compared to those who are currently in their 50 s or 60 s. A negative association between age and level of educational attainment has also been well-documented [15]. These reports suggest the importance of identifying age groups that may benefit from additional efforts on the part of health professionals to better disseminate genetic information in a manner that is appropriate and useful to their patients. Increasing awareness among health and genetic service providers about potential age differences is likely to be the 
initial step in such efforts. In order for newly emerging genetic information to be used effectively in health care and public health efforts, it is important to first gain an understanding of the social contexts in which it is intended to be used so that the extent of the potential difficulties associated with disseminating complex genetic information can be assessed.

Most previous studies have evaluated genetic knowledge associated with specific genetic tests such as cystic fibrosis [24, 25], maternal serum screening [26] and breast cancer [27]. Previous studies have also reported the development of measures of general genetic knowledge [28] or genetic literacy [11] in the U.S.; however, age differences were not the primary interest of these studies. Studies conducted outside of the U.S. have shown an association between younger age and higher general genetic knowledge (e.g. about heredity, genetic tests, genetic determinism) among Dutch [29] and Finn [30] adults as well as higher genetic literacy (i.e. genetic terminology, contextual understanding) among younger Japanese than older [31]. To our knowledge, studies evaluating differences by age in general knowledge about genetics and heredity among a population at average disease risk have not been conducted in the U.S. in recent years. Assessing preexisting knowledge, beliefs and skills pertinent to emerging genetic information, and how they may differ among individuals in different age groups, is a critical first step toward understanding the extent to which unique efforts to better inform certain population subgroups will be needed.

In addition to their health literacy, individuals' beliefs and perceptions about diseases, such as perceived controllability and causal attributions, determine how they react to health information [32], and this is likely to be critical in the context of genetics. Causal attribution to genetics has been associated with lower perceived preventability of an illness [33] and may influence individuals' motivations to engage in health-related behaviors [34]. Understanding such belief systems among the population has important implications for how genetic information is received and potentially used by the public. These beliefs are considered dynamic and are influenced by various factors including previous personal or family experiences with illnesses, education, cultural beliefs, and information received by others or the media [35]. Increasing availability of genetic information is likely to influence these illness beliefs and to further impact how individuals act in response to this new information. Previous findings on the association between age and genetic knowledge [29, 31] suggest that older individuals may be exposed to genetic information to a lesser extent, and thus, may have different genetic beliefs than younger individuals. Investigating potential age differences in such causal beliefs (e.g., causation due to genetics and behavioral factors) will provide additional information for determining optimal strategies to provide genetic information.

Limited research exists in these areas. However, as the clinical utility of genetic susceptibility information for common complex diseases is expected to increase [36], it is imperative to understand the preexisting knowledge, skills and perceptions about genetics among various subgroups of the population to allow this new information to reach all groups. New genetic information continues to emerge in our society, thus, continuing efforts to evaluate knowledge levels and perceptions about genetic information among age subgroups are needed.

This study examined the levels of genetic knowledge, health literacy and beliefs about causation of health conditions (genes and behavioral factors) among individuals in different age groups using information obtained from a large community-based general population sample in the U.S. It has been reported that provision of genetic risk information, an effort to increase genetic knowledge, was associated with stronger endorsement of genetics as a disease cause [33]. Furthermore, belief in genetics as a cause of disease may lead individuals to discount the role of behaviors in disease development [33]. Thus, individuals' levels of genetic knowledge may mediate the levels of genetic as well as behavioral causal beliefs. The potential role of genetic knowledge as a mediator in the hypothesized association between age and causal beliefs was evaluated, while controlling for such covariates as gender, race and place of birth, in order to gain a clearer understanding of age differences in these beliefs.

\section{Methods}

\section{Design and Study Setting}

The participants in this study were recruited between August 2008 and November 2008 through 8 community health centers in the Suffolk County Department of Health Services (SCDHS) network of family health centers located in the state of New York. These centers provide no/low cost health care on a sliding scale for uninsured/underinsured county residents as well as accepting Medicaid and other public insurance. Patients aged 18 years or older, who could speak, read and write in English or Spanish were eligible to participate. This community-based sample included a diverse group of patients in terms of their race/ethnicity and educational attainment. All participants completed one survey in ei- 
ther English or Spanish to assess a variety of factors including health literacy, genetic knowledge, causal beliefs about health conditions, and sociodemographic characteristics.

\section{Measures}

Genetic Knowledge. Genetic knowledge was assessed using a five-item measure used in previous studies $[28,37]$. This measure was selected because it was developed to assess basic knowledge about genetics among the general public across diverse populations rather than among student populations and was validated against educational attainment and attitudes toward genetic discrimination [28]. High reliability of these items was also reported in a later study involving relatives of lung cancer patients [37]. Participants indicated whether each of 5 statements was true or false: once a genetic marker for a health condition is found in a person, the condition can be prevented or cured; if a person has a genetic marker for a health condition, the person will always get the condition; only mothers can pass on genetic conditions; people who have genetic marker for a disease are unhealthy; and a person's health habits can influence whether or not their genes cause disease. The number of correct answers was calculated for each participant; possible scores ranged from 0-5 (Cronbach's alpha $=0.67$.

Health Literacy. The Newest Vital Sign (NVS) was used to measure participants' health literacy [38]. This measure consists of 6 items assessing reading comprehension and numeracy, based on information contained on a food nutrition label, and is available in English and Spanish. The validity [38] and sensitivity of this measure in detecting limited health literacy [39] as compared to previously established health literacy measures (i.e. REALM and S-TOFHLA) [40, 41] have been reported. The number of correct answers was calculated for each participant to obtain a health literacy score ranging from $0-6$ (Cronbach's alpha $=0.58$ ). Four or more correct answers indicate adequate health literacy.

Causal Beliefs. Six items were used to assess participants' beliefs about the extent to which 3 health conditions (i.e. heart disease, diabetes and a person's weight) are caused by 'genes' or 'health habits such as diet, exercise and smoking' using 5-point response options ranging from 'not at all' to 'completely' [42]. Responses were dichotomized to indicate a strong causal belief ('completely' or 'mostly') for genes and for health habits. Responses to each of these items were used as 6 independent variables in the analyses.

Respondent Characteristics. Respondent characteristics collected in the survey included age, gender, race/ethnicity, educational attainment, country of birth, self-reported height and weight, and whether they had ever been diagnosed with diabetes or heart disease. Indicator variables were created for female gender, $3 \mathrm{racial} / \mathrm{ethnic}$ groups (Black, Hispanic and Other), having high school education/GED or higher, being born in the U.S., completing the survey in Spanish, and having been diagnosed with diabetes/heart disease. Self-reported height and weight values were used to calculate body mass index (BMI) as self-reported measures have been reported to highly correlate with actual measures and be reliable among British middle-aged adults $(r>0.9)$ [43] and U.S. adults in manufacturing and service industries ( $\mathrm{r}=$ 0.99 ) [44]. Age was categorized into 4 groups based on the distribution of the sample: $18-25$ years of age, 26-35 years, 36-49 years, and 50 years of age or older.

Public Health Genomics 2011;14:307-316

\section{Data Analysis}

Bivariate analyses were conducted first to examine the associations between each of the outcome variables (genetic knowledge, health literacy, causal beliefs) and the primary predictor, age of the participants. Pearson Chi-squared $\left(\chi^{2}\right)$ tests were used to assess associations between categorical variables. Following these analyses, multivariable models were built for the significantly associated variables controlling for potential confounding variables. Based on the findings of previous studies [19, 29, 31], sociodemographic factors considered as potential confounders in health literacy and genetic knowledge models included gender, race, levels of education, language of survey administration, and place of birth. Multiple linear regression models were fitted for the continuous outcomes (genetic knowledge, health literacy) using gender, race, educational attainment, survey language, and place of birth as covariates; regression coefficients and respective $p$ values are reported. For the dichotomous outcomes (causal beliefs), multivariable logistic regression models were fitted using gender, race and place of birth as covariates, and the potential mediating role of genetic knowledge was evaluated. Furthermore, individuals' previous experiences with a health condition have been shown to influence these beliefs [35]. Thus, self-reported diabetes and heart disease diagnoses and body mass index (BMI) were also considered as covariates in the relevant multivariable models for the causal beliefs. Odds ratios as well as their 95\% confidence intervals are reported. Indicators for the 3 older age groups were entered in these models along with the covariates. The youngest age group, 18-25 years, served as a referent group. Analyses were conducted using Stata Statistical Software version 8.0 (College Station, TX). All tests were conducted at the $\alpha=0.05$ level of significance. The intraclass correlations (ICC) of the outcome variables, which indicate the extent to which data may cluster within the health centers, ranged from 0-0.04 (smaller than the cut point of 0.10 suggested by Lee [45]). Given that there was little to no clustering exhibited within health centers, the nested structure of the data was not adjusted for in the analyses [45].

\section{Results}

\section{Respondent Characteristics}

Out of 1,318 participants, 1,061 (80.5\%) individuals completed all components of the survey. The demographic characteristics of 257 individuals who did not complete surveys did not differ significantly from those who completed them. 90 participants were excluded for missing data on age; the demographic characteristics of the participants included in the analyses $(n=971)$ are presented in table 1 . The average age of the participants was 37.4 years ( $\mathrm{SD}=13.8)$; age ranged from $18-91$. The majority of the participants were female $(74.5 \%)$ and were born in the U.S. (57.2\%). Most completed surveys in English (82.5\%). About $17.5 \%$ indicated that they had less than a high school level of education, while $37.0 \%$ reported having a high school degree or GED and $45.5 \%$ reported having a college degree or higher. The largest proportion of the 
participants identified themselves as Hispanic (34.6\%), followed by black (30.2\%) and white (26.9\%). Participants in the 'other' race category included Asian/Pacific Islander (3.2\%) and Native American (2.3\%). These characteristics are representative of the SCDHS network of family health centers patient population. The average BMI among the respondents was $28.7(\mathrm{SD}=16.1)$. Fourteen percent and $10 \%$ of the respondents had ever been diagnosed with diabetes and heart disease, respectively.

Table 1. Demographic characteristics of respondents $(n=971)$

\begin{tabular}{ll}
\hline Age (years) & \\
$18-25$ & $24.4 \%$ \\
$26-35$ & $27.2 \%$ \\
$36-49$ & $27.0 \%$ \\
$50+$ & $21.4 \%$ \\
Gender & \\
Male & $25.5 \%$ \\
Female & $74.5 \%$ \\
Race/ethnicity & \\
White (non-Hispanic) & $26.9 \%$ \\
Black (non-Hispanic) & $30.2 \%$ \\
Hispanic & $34.6 \%$ \\
Other race & $8.3 \%$ \\
Education level & \\
Less than high school & $17.5 \%$ \\
High school degree/GED & $37.0 \%$ \\
College degree or higher & $45.5 \%$ \\
Health status & \\
Diagnosed with diabetes & $13.9 \%$ \\
Diagnosed with heart disease & $10.3 \%$ \\
Survey in English & $82.5 \%$ \\
Born in the U.S. & $57.2 \%$ \\
\hline
\end{tabular}

\section{Genetic Knowledge}

The average score for genetic knowledge among all participants was $2.7(\mathrm{SD}=1.4)$. The average was the highest for the youngest age group $(18-25$ years $=2.9, \mathrm{SD}=$ 1.4 ) and lowest for the oldest age group (50 years or older $=2.6, \mathrm{SD}=1.4)($ table 2$)$. The results of the multivariable analysis based on 905 participants without missing data (table 3) indicate that the average number of correct answers decreased with each unit increase in age group controlling for sociodemographic confounders. The number of correct answers decreased by 0.31 ( $\mathrm{p}=$ $0.011)$ for those aged 26-35 years, $0.38(\mathrm{p}=0.002)$ for those aged $36-49$ years and $0.50(\mathrm{p}<0.001)$ for those aged 50 years or older compared to those in the youngest group, 18-25 years.

\section{Health Literacy}

The average NVS score among all participants was 2.7 $(\mathrm{SD}=1.8)$, indicating potential limited health literacy [29]. The average score was the highest for the youngest age group $(=3.1, \mathrm{SD}=1.8)$ and lowest for the oldest age group $(=2.6, \mathrm{SD}=1.9)$. The proportions of participants who scored 4 or higher, indicating that they likely have adequate health literacy, were $38.8 \%$ for those aged $18-25$, followed by $33.9 \%$ ( $26-35$ years), $33.5 \%$ ( $36-49$ years), and $32.5 \%$ (50 years and older). The results of multivariable analysis based on 917 participants without missing data are shown in table 3 . The average NVS scores were significantly lower among participants in the oldest age group (50 years or older) compared to the youngest group (18-25 years of age) controlling for gender, race, education, and cultural factors (survey language and location of birth).

Table 2. Levels of health literacy, genetic knowledge and causal beliefs by age cohort

\begin{tabular}{|c|c|c|c|c|c|c|c|c|}
\hline \multirow{3}{*}{$\begin{array}{l}\text { Health literacy (NVS score) } \\
\text { Genetic knowledge }\end{array}$} & \multicolumn{2}{|c|}{$\begin{array}{l}\text { Age } 18-25 \\
\text { Mean (SD) }\end{array}$} & \multicolumn{2}{|c|}{$\begin{array}{l}\text { Age } 26-35 \\
\text { Mean }(\mathrm{SD})\end{array}$} & \multicolumn{2}{|c|}{$\begin{array}{l}\text { Age } 36-49 \\
\text { Mean }(S D)\end{array}$} & \multicolumn{2}{|c|}{$\begin{array}{l}\text { Age } 50+ \\
\text { Mean }(\mathrm{SD})\end{array}$} \\
\hline & 3.07 & 1.77 & 2.71 & 1.85 & 2.77 & 1.82 & 2.57 & 1.92 \\
\hline & 2.94 & 1.35 & 2.61 & 1.42 & 2.61 & 1.45 & 2.57 & 1.36 \\
\hline \multicolumn{9}{|l|}{ Strong causal beliefs } \\
\hline Diabetes: genes & 145 & $58.2 \%$ & 165 & $61.1 \%$ & 150 & $54.2 \%$ & 111 & $52.6 \%$ \\
\hline Diabetes: behaviors & 141 & $56.9 \%$ & 159 & $59.8 \%$ & 172 & $61.9 \%$ & 121 & $57.6 \%$ \\
\hline Heart disease: genes & 118 & $47.6 \%$ & 137 & $51.5 \%$ & 146 & $53.1 \%$ & 108 & $51.4 \%$ \\
\hline Heart disease: behaviors & 149 & $59.8 \%$ & 183 & $68.8 \%$ & 187 & $67.5 \%$ & 132 & $63.2 \%$ \\
\hline Body weight: genes & 76 & $30.7 \%$ & 100 & $37.5 \%$ & 113 & $41.1 \%$ & 88 & $42.3 \%$ \\
\hline Body weight: behaviors & 174 & $69.9 \%$ & 191 & $71.3 \%$ & 199 & $72.1 \%$ & 119 & $56.7 \%$ \\
\hline
\end{tabular}


Table 3. Multivariable models of levels of health literacy (NVS) and genetic knowledge by age cohort

\begin{tabular}{|c|c|c|c|c|c|c|}
\hline & \multicolumn{3}{|c|}{ Health literacy $(\mathrm{NVS})(\mathrm{n}=917)$} & \multicolumn{3}{|c|}{ Genetic knowledge $(n=905)$} \\
\hline & coefficient & s.e. & $\mathrm{p}$ & coefficient & s.e. & $\mathrm{p}$ \\
\hline Age: $26-35$ & -0.137 & 0.145 & 0.344 & -0.309 & 0.121 & 0.011 \\
\hline Age: $36-49$ & -0.224 & 0.144 & 0.121 & -0.377 & 0.120 & 0.002 \\
\hline Age: $50+$ & -0.691 & 0.159 & $<0.001$ & -0.498 & 0.131 & $<0.001$ \\
\hline Female & 0.110 & 0.120 & 0.362 & 0.047 & 0.100 & 0.638 \\
\hline Black & -0.195 & 0.138 & $<0.001$ & -0.298 & 0.115 & 0.010 \\
\hline Hispanic & -0.755 & 0.167 & $<0.001$ & -0.290 & 0.139 & 0.037 \\
\hline Other race & -0.454 & 0.209 & 0.030 & -0.262 & 0.175 & 0.134 \\
\hline High school or higher & 0.862 & 0.106 & $<0.001$ & 0.641 & 0.088 & $<0.001$ \\
\hline Survey in Spanish & -0.899 & 0.189 & $<0.001$ & -0.349 & 0.157 & 0.026 \\
\hline Born in the U.S. & 0.800 & 0.132 & $<0.001$ & 0.416 & 0.110 & $<0.001$ \\
\hline
\end{tabular}

Table 4. Multivariable models of causal beliefs about person's body weight by age cohort

\begin{tabular}{|c|c|c|c|c|c|c|}
\hline & \multicolumn{3}{|c|}{ Genes $(\mathrm{n}=775)$} & \multicolumn{3}{|c|}{ Behavioral factors $(\mathrm{n}=777)$} \\
\hline & OR & $95 \% \mathrm{CI}$ & $\mathrm{p}$ & OR & $95 \% \mathrm{CI}$ & $\mathrm{p}$ \\
\hline Age: $26-35$ & 1.368 & $0.873,2.143$ & 0.172 & 1.002 & $0.636,1.578$ & 0.995 \\
\hline Age: $36-49$ & 1.589 & $1.025,2.466$ & 0.039 & 1.110 & $0.709,1.740$ & 0.647 \\
\hline Age: $50+$ & 1.869 & $1.180,2.961$ & 0.008 & 0.551 & $0.350,0.867$ & 0.010 \\
\hline Female & 0.702 & $0.503,0.981$ & 0.038 & 1.252 & $0.889,1.764$ & 0.198 \\
\hline BMI & 1.024 & $1.000,1.047$ & 0.046 & 1.001 & $0.977,1.025$ & 0.950 \\
\hline Genetic knowledge & 0.998 & $0.889,1.119$ & 0.967 & 1.249 & $1.111,1.404$ & $<0.001$ \\
\hline Black & 1.115 & $0.751,1.656$ & 0.591 & 0.758 & $0.508,1.131$ & 0.175 \\
\hline Hispanic & 1.034 & $0.662,1.615$ & 0.883 & 0.857 & $0.542,1.355$ & 0.510 \\
\hline Other race & 1.601 & $0.896,2.861$ & 0.112 & 0.542 & $0.300,0.977$ & 0.042 \\
\hline Born in the U.S. & 0.475 & $0.333,0.679$ & $<0.001$ & 0.650 & $0.446,0.948$ & 0.025 \\
\hline
\end{tabular}

\section{Causal Beliefs}

The proportions of respondents who indicated strong genetic or behavioral causal beliefs regarding the 3 conditions (diabetes, heart disease and body weight) are shown in table 2. About $50-65 \%$ of the participants indicated strong genetic and behavioral causal beliefs for diabetes and heart disease. There were no significant age differences in genetic $\left(\chi^{2}=17.45, \mathrm{df}=12, \mathrm{p}=0.13\right)$ and behavioral $\left(\chi^{2}=13.05, \mathrm{df}=12, \mathrm{p}=0.37\right)$ causal beliefs for diabetes. Similarly, there were no significant age differences in genetic $\left(\chi^{2}=9.23, \mathrm{df}=12, \mathrm{p}=0.68\right)$ and behavioral $\left(\chi^{2}=20.12, \mathrm{df}=12, \mathrm{p}=0.07\right)$ causal beliefs for heart disease. For causal beliefs about body weight, $38 \%$ of participants overall had strong genetic causal beliefs and $68 \%$ had strong behavioral causal beliefs. The bivariate analy- sis showed significant age differences in both behavioral causal belief $\left(\chi^{2}=42.05, \mathrm{df}=12, \mathrm{p}<0.01\right)$ and genetic causal belief $\left(\chi^{2}=24.48, \mathrm{df}=12, \mathrm{p}=0.02\right)$ about body weight.

The results of the multivariable analyses shown in table 4 indicate that participants in the 2 older age groups were 1.87 (50 years and older) and 1.59 (ages 36-49 years) times more likely to have strong genetic causal beliefs for a person's weight compared to those in the youngest age group (18-25 years). In terms of the behavioral causal belief, participants in the oldest age group were significantly less likely $(\mathrm{OR}=0.55)$ to believe that health habits such as diet, exercise and smoking cause a person's body weight compared to those in the youngest group. Results also show that those with higher genetic knowledge were 
more likely to have a strong behavioral causal belief $(\mathrm{OR}=1.25)$. However, genetic knowledge did not mediate the associations between age and behavioral causal beliefs, and this variable was significant only in the behavioral causal belief model.

\section{Discussion}

This study evaluated whether there are differences in genetic knowledge, health literacy and beliefs about the causes of health conditions (genetic and behavioral causes) among community health center patients in different age cohorts. Consistent with the existing literature that reports a negative linear association between age and health literacy (see Berkman [19] for a comprehensive review), health literacy was lower among individuals in the oldest age group compared to youngest in this current study. Because this oldest group included individuals ages 50 years and older, it is likely that cohort effects such as changes in educational opportunities [19] are being observed in these findings rather than aging effects, such as decreased exposure to reading [46] and increased prevalence of chronic health conditions (e.g. diabetes, hypertension, history of stroke) that can interfere with information processing [16]. Similarly, levels of genetic knowledge were significantly lower among respondents in the 3 older age groups compared to the youngest with the average genetic knowledge score being the lowest among those in the oldest group. These observed differences are also likely to be accounted for by changing educational approaches as genetic science has advanced dramatically over the years. It is important, therefore, that health professionals do not assume that all individuals possess the knowledge about genetics that is currently being taught in U.S. educational systems. Findings of this study suggest the importance of increasing awareness among health professionals that individuals in older age groups may be exposed to genetic information to a lesser extent and possess lower general health literacy than younger individuals, and that efforts to help them better understand this type of information may be needed. For example, providing additional background information regarding genetics or encouraging them to seek assistance from younger family members, friends or health professionals may help them benefit from provided genetic information more fully.

Our findings suggest the importance of assessing genetic knowledge when providing health information con- cerning genetics to individuals in older age groups. Informing older individuals about the rapid advancement of genetic research may motivate them to ask more questions. Providing basic genetic information in plain language terms may also help increase understanding of the provided information. Raising awareness among health professionals about potential age differences in genetic knowledge and health literacy will be essential in initiating these efforts. These results also suggest that the contents of the health information need to be evaluated to determine what types of basic genetic knowledge are assumed to be possessed by the individuals to whom the information is being provided. It is also important to note that information regarding the genetic knowledge individuals need in order to make informed health decisions is not readily available [47] and such understanding is essential in developing effective interventions. Further studies to determine with which specific knowledge domains older individuals may have difficulty are also important for the development of tailored materials and strategies that will help in their healthcare decision-making. Upon gaining such understanding, evaluating the utility of the intervention strategies that have been successfully used in health literacy research (e.g. avoiding technical jargon, using simple sentence structure) may be helpful [48].

The results of this study demonstrated that about the same proportions of participants (60\%) expressed strong causal beliefs for genes and for behavioral factors regarding diabetes. For heart disease, about half of the participants expressed strong genetic causal beliefs and $65 \%$ had strong behavioral causal beliefs. There were no significant age differences in these beliefs, suggesting a common model of disease causation regardless of the participant's age. Regarding causal beliefs for a person's body weight, although a majority (68\%) reported strong behavioral causal beliefs, only about $38 \%$ indicated strong genetic causal beliefs. Furthermore, participants in the oldest age group were significantly more likely to believe in genetic causation of a person's body weight and significantly less likely to believe in behavioral causation compared to those in the youngest age group controlling for such demographic characteristics as gender, race and BMI. This may mean that older individuals feel less control over their body weight, potentially reflecting their experiences with slowing metabolism as they age. It has been reported that perception of behavioral factors as causes of illness as opposed to genetic factors may help motivate individuals to engage in health promoting behaviors [33]. Thus, strong genetic causal beliefs observed 
among those in the older age group may cause them to engage in health promoting behaviors to a lesser extent. Providing appropriate information about the role of genes vs. behaviors and emphasizing the importance of behavioral factors in managing body weight may help facilitate health promoting behaviors among these individuals.

The findings of this study further showed that higher levels of genetic knowledge were associated with higher likelihood of individuals endorsing behavioral factors as determinants of a person's body weight. Because 3 of the 5 items assessing genetic knowledge evaluated individuals' levels of understanding about the multifactorial causation of common complex diseases, this finding suggests that providing accurate information about the roles of both genes and behavioral factors may lead to more endorsement of the behavioral factors, which may then help motivate individuals to engage in health promoting behaviors to address the health condition [33]. On the other hand, levels of genetic knowledge were not associated with endorsing genetic causal beliefs. There has been concern within the field of public health genomics regarding the provision of genetic risk information and its potential impact on recipients' genetic fatalism, or belief that there is nothing one can do about a condition that is caused by genes $[34,49]$. However, the findings of this study suggest that providing accurate genetic information, especially about multifactorial causation of common diseases, may actually lead to increases in perceived importance of behavioral factors in common health conditions. Further studies would be needed to determine whether higher levels of genetic knowledge can lead to higher levels of health promoting behaviors associated with common complex diseases.

\section{Limitations}

This study employed a cross-sectional design, thus, it cannot be determined whether differences in health literacy and knowledge levels are a result of an aging effect (e.g. increasing difficulty in completing cognitive tasks) or cohort effect (e.g. differences in educational opportunity). Conducting longitudinal studies to follow-up with participants over time and considering other potential confounders (e.g. cognitive ability and visual acuity) will help answer this question. Although we were interested in age differences, we did not have a large number of participants who are generally considered 'old' (e.g. 65 years or older). Future studies aiming to investigate whether levels of genetic knowledge are lower among such older adults who are likely to face unique needs as they maneu- ver through healthcare systems may consider oversampling this population.

Participants in this study were suburban residents from a specific county in the U.S., thus the findings cannot be generalized to the general public from other parts of the country that may have different experiences and cultural backgrounds. Finally, the limitations of the measurement tools need to be carefully considered. All responses were based on participants' self-reports. Measures of general genetic knowledge are limited, and the genetic knowledge items used here were adapted from a measure developed based on expert opinion and factor analyses using a sample from a Midwestern city in the U.S. Although the reliability and validity of this measure have been documented, it is not clear whether it assesses the types of knowledge individuals actually need to make informed decisions associated with genetic information provided in health care. Furthermore, as genetic science continues to advance rapidly, continuing efforts to develop appropriate measures of genetic knowledge are needed.

\section{Conclusions}

The findings of this study showed that the levels of knowledge about genetics differ among community health center patients of different ages. This has implications for public health efforts as health professionals aim to translate the findings of genetic science to health practices. The findings suggest that individuals in older age groups may benefit from additional information to compensate for genetic education they may not have received when they were younger. Increasing the awareness about rapidly advancing genetic science among these individuals may also be beneficial in encouraging them to ask more questions. It is also important that health professionals be aware of such potential age differences in individuals' ability to comprehend and use health information involving genetics. In-depth research will be needed to identify information that is pertinent and important for individuals to benefit from health information provided to them as well as to identify effective methods to deliver such needed information. It has been suggested that differences in health status observed among subgroups (e.g. age, race) in our country may partly be due to the differences in the levels of health literacy. Health literacy, including knowledge, is a modifiable factor that can be intervened upon to improve the understanding of health information among 
the general public that, in turn, may help reduce health disparities through equal utilization of health information and care resources. It is challenging to communicate genetic information as the science continues to advance rapidly in our society, thus, continuing efforts to understand the needs of the public, and particularly its older members, are imperative.

\section{Acknowledgements}

This work was supported by the Intramural Research Program of the National Human Genome Research Institute at the National Institutes of Health. We thank the patients and staff at the community health centers for their participation in the study. The views expressed in this article are those of the authors and do not necessarily reflect the official policy or position of the Department of Health and Human Services, nor the U.S. Government.

\section{References}

1 Christensen K, Murray JC: Focus on research: what genome-wide association studies can do for medicine. New Engl J Med 2007;356:1094-1097.

2 Guttmacher AE, Collins FS: Welcome to the genomic era. New Engl J Med 2003;349:996998.

-3 Collins FS, Green ED, Guttmacher AE, Guyer MS: A vision for the future of genomics research. Nature 2003;422:835-847.

4 Wang C, Bowen DJ, Kardia SL: Research and practice opportunities at the intersection of health education, health behavior, and genomics. Health Educ Behav 2005;32:686701.

5 Lanie AD, Jayaratne TE, Sheldon JP, Kardia SL, Anderson ES, Feldbaum M, Petty EM: Exploring the public understanding of basic genetic concepts. J Genet Couns 2004;13: 305-320.

6 Emery J, Kumar S, Smith H: Patient understanding of genetic principles and their expectations of genetic services within the NHS: a qualitative study. Community Genet 1998;1:78-83.

7 Human Genetics Commission: Public attitudes to human genetics information: people's panel quantitative study conducted for the human genetics commission, London. 2001. http://www.Hgc.Gov.Uk.London.

8 Gaskell G, Allum N, Bauer M, Durant J, Allansdottir A, Bonfadelli H, Boy D, De Cheveigné $S$, Fjaestad B, Gutteling JM, Hampel J, Jelsøe E, Jesuino JC, Kohring M, Kronberger N, Midden C, Nielsen TH, Przestalski A, Rusanen T, Sakellaris G, Torgersen H, Twardowski T, Wagner W: Biotechnology and the European public. Nat Biotechnol 2000;18:935-938.

-9 Sturgis P, Cooper H, Fife-Schaw C: Attitudes to biotechnology: estimating the opinions of a better-informed public. New Genet Soc 2005; 24:31-56.

10 Guttmacher AE, Collins FS, Carmona RH: The family history - more important than ever. New Engl J Med 2004;351:2333-2336.

- 11 Bowling BV, Acra EE, Wang L, Myers MF, Dean GE, Markle GC, Moskalik CL, Huether CA: Development and evaluation of a genetics literacy assessment instrument for undergraduates. Genetics 2008;178:15-22.
12 Lea DH, Kaphingst KA, Bowen DJ, Lipkus I, Hadley DW: Communicating genetic and genomic information: health literacy and numeracy considerations. Public Health Genomics 2010, E-pub ahead of print.

13 Kirsch I, Jungeblut A, Jenkins L, Kolstad A: Adult Literacy in America: A First Look at the Findings of the National Adult Literacy Survey, ed 3. Washington, D.C., National Center for Education, US Department of Education, 2002, vol 201.

14 Kutner M, Greenberg E, Baer J: National Assessment of Adult Literacy (NAAL): A First Look at the Literacy of America's Adults in the 21st Century (NCES 2006-470). Washington, D.C., National Center for Education Statistics, U.S. Department of Education, 2005

15 White S: Assessing the Nation's Health Literacy: Key Concepts and Findings of the $\mathrm{Na}$ tional Assessment of Adult Literacy (NAAL). Chicago, American Medical Association Foundation, 2008.

16 Baker DW, Gazmararian JA, Sudano J, Patterson $\mathrm{M}$ : The association between age and health literacy among elderly persons. J Gerontol B Psychol Sci Soc Sci 2000;55: S368-S374.

17 Kutner M, Greenberg E, Jin Y, Paulsen C: The Health Literacy of America's Adults: Results from the 2003 National Assessment of Adult Literacy. Washington, D.C., National Center for Education Statistics, U.S. Department of Education, 2006.

18 Bennett CL, Ferreira MR, Davis TC, Kaplan J, Weinberger M, Kuzel T, Seday MA, Sartor O: Relation between literacy, race, and stage of presentation among low-income patients with prostate cancer. J Clin Oncol 1998;16: 3101-3104.

19 Berkman ND, DeWalt DA, Pignone MP Sheridan SL, Lohr KN, Lux L, Sutton SF, Swinson T, Bonito AJ: Literacy and Health Outcome. Evidence report/technology assessment No. 87. Rockville, Agency for Healthcare Research and Quality, U.S. Department of Health and Human Services, 2004.
20 Proceedings of the 2005 White House Conference on Aging Mini-Conference on Health Literacy and Health Disparities. Chicago, American Medical Association, 2005.

21 Centers for Disease Control and Prevention, National Center for Health Statistics: Health conditions: chronic conditions, ages 18+: US 1997-2008. Health Data Interactive. 2008. http://www.cdc.gov/nchs/hdi.htm.

22 Gornick ME: A decade of research on disparities in medicare utilization: lessons for the health and health care of vulnerable men. Am J Public Health 2003;93:753-759.

23 Morgan L, Kunkel S: Aging: The Social Context, ed 2. Thousand Oaks, Pine Forge Press, 2001.

24 Bernhardt BA, Chase GA, Faden RR, Geller G, Hofman KJ, Tambor ES, Holtzman NA: Educating patients about cystic fibrosis carrier screening in a primary care setting. Arch Fam Med 1996;5:336-340.

25 Henneman L, Bramsen I, Van Der Ploeg HM, Ten Kate LP: Preconception cystic fibrosis carrier couple screening: impact, understanding, and satisfaction. Genet Test 2002;6:195-202.

26 Goel V, Glazier R, Holzapfel S, Pugh P, Summers A: Evaluating patient's knowledge of maternal serum screening. Prenatal Diag 1996;16:425-430.

27 Bottorff JL, Ratner PA, Balneaves LG, Richardson CG, McCullum M, Hack T, Chalmers $\mathrm{K}$, Buxton J: Women's interest in genetic testing for breast cancer risk: the influence of sociodemographics and knowledge. Cancer Epidemiol Biomarkers Prev 2002;11:89-95.

28 Furr LA, Kelly SE: The Genetic Knowledge Index: developing a standard measure of genetic knowledge. Genet Test 1999;3:193-199.

29 Henneman L, Timmermans DR, van der Wal G: Public experiences, knowledge and expectations about medical genetics and the use of genetic information. Community Genet 2004;7:33-43.

30 Jallinoja P, Aro AR: Knowledge about genes and heredity among Finns. N Genet Soc 1999;18:101-110. 
- 31 Ishiyama I, Nagai A, Muto K, Tamakoshi A, Kokado M, Mimura K, Tanzawa T, Yamagata Z: Relationship between public attitudes toward genomic studies related to medicine and their level of genomic literacy in Japan. Am J Med Genet A 2008;146A:1696-1706.

32 Diefenbach MA, Leventhal H: The commonsense model of illness representation: theoretical and practical considerations. J Soc Distress Homel 1996;5:11-38.

-33 Senior V, Marteau TM, Weinman J: Impact of genetic testing on causal models of heart disease and arthritis: an analogue study. Psychol Health 2000;14:1077-1088.

- 34 Senior V, Marteau TM, Peters TJ: Will genetic testing for predisposition for disease result in fatalism? A qualitative study of parents responses to neonatal screening for familial hypercholesterolaemia. Soc Sci Med 1999;48:1857-1860.

35 Shiloh S: Illness representations, self-regulation, and genetic counseling: a theoretical review. J Genet Couns 2006;15:325-337.

- 36 Emery J, Barlow-Stewart K, Metcalfe SA, Sullivan D: Genetics and preventive health care. Aust Fam Physician 2007;36:808-811.
37 O’Neill SC, White DB, Sanderson SC, Lipkus IM, Bepler G, Bastian LA, McBride CM: The feasibility of online genetic testing for lung cancer susceptibility: uptake of a web-based protocol and decision outcomes. Genet Med 2008;10:121-130.

38 Weiss BD, Mays MZ, Martz W, Castro KM, DeWalt DA, Pignone MP, Mockbee J, Hale FA: Quick assessment of literacy in primary care: the newest vital sign. Ann Fam Med 2005;3:514-522.

39 Osborn CY, Weiss BD, Davis TC, Skripkauskas S, Rodrigue C, Bass PF, Wolf MS: Measuring adult literacy in health care: performance of the newest vital sign. Am J Health Behav 2007;31(suppl 1):36-46.

40 Davis TC, Long SW, Jackson RH, Mayeaux EJ, George RB, Murphy PW, Crouch MA: Rapid estimate of adult literacy in medicine: a shortened screening instrument. Fam Med 1993;25:391-395.

41 Parker RM, Baker DW, Williams MV, Nurss JR: The test of functional health literacy in adults: a new instrument for measuring patients' literacy skills. J Gen Intern Med 1995; 10:537-541.

-42 McBride CM, Alford SH, Reid RJ, Larson EB, Baxevanis AD, Brody LC: Characteristics of users of online personalized genomic risk assessments: implications for physician-patient interactions. Genet Med 2009;11:582587.
43 Spencer EA, Appleby PN, Davey GK, Key TJ: Validity of self-reported height and weight in 4,808 EPIC-Oxford participants. Public Health Nutr 2002;5:561-565.

-44 Jeffery RW: Bias in reported body weight as a function of education, occupation, health and weight concern. Addict Behav 1996;21: 217-222.

45 Lee VE: Using hierarchical linear modeling to study social contexts: the case of school effects. Educ Psychol 2000;35:125-141.

46 Joseph M: Literacy of 90 million is deficient: U.S. Survey sounds alarm over skills in reading, arithmetic. The Washington Post, September 30, 1993, A01.

-47 Condit CM: Public understandings of genetics and health. Clin Genet 2010;77:1-9.

48 Maibach E, Parrott R: Designing Health Messages: Public Health Practice and Communication Theory. Newbury Park, Sage Publications, 1995.

49 Wright AJ, Weinman J, Marteau TM: The impact of learning of a genetic predisposition to nicotine dependence: an analogue study. Tob Control 2003;12:227-230. 